\title{
AVALIAÇÃO MORFOMÉTRICA DOS TÚBULOS CONTORCIDOS PROXIMAIS DE RATOS DIABÉTICOS TRATADOS COM NEEM (Azadirachta indica, A. Juss) E ESTREPTOZOOTOCINA 6 CH
}

\author{
ORTOLAN, Mariana Dulce Delle Vedove ${ }^{1}$ \\ PACHECO, Maria Rita ${ }^{2}$ \\ GIRARDI, Annita Morais ${ }^{3}$ \\ BARALDI-ARTONI, Silvana Martinez ${ }^{4}$ \\ SANTOS, Edanir dos ${ }^{5}$ \\ BARREIRO, Fabiana Ribeiro ${ }^{6}$
}

\begin{abstract}
RESUMO: Foram avaliados os efeitos de extratos de Azadirachta indica, A. Juss e da estreptozootocina em ultra alta diluições em sistemas dinamizados sobre a morfometria dos túbulos contorcidos proximais de ratos com diabetes mellitus induzida por estreptozootocina, já que este segmento do néfron absorve a totalidade da glicose contida no filtrado glomerular. Os resultados morfométricos obtidos indicaram diferenças significativas entre os tratamentos para os parâmetros mensurados no núcleo das células dos túbulos contorcidos proximais, bem como na espessura das células destes túbulos. O grupo controle branco apresentou os maiores valores médios para todos os parâmetros analisados, comparado aos demais grupos experimentais.
\end{abstract}

Palavras-chave: Azadirachta indica, diabetes mellitus, estreptozootocina, morfometria, rim.

\section{MORPHOMETRIC EVALUATION OF THE PROXIMAL CONVOLUTED TUBULES OF DIABETIC RATS TREATED WITH NEEM (Azadirachta indica, A. Juss) AND STREPTOZOTOCIN 6 CH}

SUMMARY: The effects of extracts from Azadirachta indica, A. Juss, and streptozotocin in extreme high dilutions in dinamized systems on proximal convoluted tubules of rats with diabetes mellitus induced by streptozotocin were evaluated, because this nephron segment absorbs all the glucose from the glomerular filter. The morphometric results indicated significant differences among the treatments for the measured parameters in cell nucleus of the proximal convoluted tubules and in thickness of the tubule cells. The white control group presented higher mean values for the analyzed parameters than the other experimental groups.

Keywords: Azadirachta indica, diabetes mellitus, streptozotocin, morphometry, kidney.

\footnotetext{
${ }^{1}$ Faculdade de Ciências Agrárias e Veterinárias - UNESP Jaboticabal

2 Prof. Dr. da Universidade Estadual Paulista Júlio de Mesquita Filho- Faculdade de Ciências Agrárias e Veterinárias - UNESP Jaboticabal

${ }^{3}$ Mestranda do Programa de Pós-Graduação em Medicina Veterinária, área de Clínica Médica, na Faculdade de Ciências Agrárias e Veterinárias de Jaboticabal - Unesp

${ }^{4}$ Livre docente da Universidade Estadual Paulista Júlio de Mesquita Filho- Faculdade de Ciências Agrárias e Veterinárias - UNESP Jaboticabal

${ }^{5}$ Dr. Em Toxicologia- Prof. Universidade Estadual Paulista Júlio de IMesquita Filho- Faculdade de Ciências Agrárias e Veterinárias - UNESP Jaboticabal

${ }^{6}$ Mestranda em Medicina Veterinária Preventiva, bolsista da Fundação de Amparo à Pesquisa do Estado de São Paulo - FAPESP. Faculdade de Ciências Agrárias e Veterinárias - UNESP Jaboticabal
} 


\section{INTRODUÇÃO}

Várias espécies vegetais foram incorporadas à medicina tradicional devido ao seu uso experimental, compilando resultados positivos ou negativos quanto à sua ação farmacológica (Di STASI, 1996). Assim, julga-se importante o estudo de plantas medicinais, incentivado pela própria OMS, principalmente por razões econômicas e sociais (MARTINS et al., 1994).

A Azadirachta indica A. Juss, planta da família Meliaceae também conhecida como Nim (Neem), é originária das regiões áridas da Índia (CHOPRA, 1958; SAXENA, 1993), muito resistente, não exigente em solo, de crescimento rápido, alcança de 10 a 15 metros de altura (SCHMUTTERER, 1990) e prefere climas tropicais (KOCH, 1990). O Nim foi introduzido no Brasil em 1993, na EMBRAPA-CNPAF (Centro Nacional de Pesquisa de Arroz e Feijão) em Goiânia - GO, com o intuito de preparação de carrapaticida para bovinos. Atualmente, sabe-se que possui uma grande concentração de terpenóides (RAGASA et al., 1997) e estes compostos são, em sua maioria, os responsáveis pelas suas ações terapêuticas. O extrato de suas folhas teve a ação hipoglicemiante mais potente quando comparada a outras plantas medicinais em ratos normais e diabéticos induzidos por estreptozotocina (CHATTOPAHYAY, 1999; ALAM et al., 1990). Khosla et al., (2000) confirmaram seu efeito hipoglicemiante em coelhos diabéticos aloxânicos tratados com extratos de folhas e óleo das sementes da Azadirachta indica e, comparando-a à glibenclamida, sugeriram que esta planta seria benéfica no controle dos níveis glicêmicos do diabetes mellitus. Porém, Rosa et al. (2010) consideraram duvidoso seu uso no controle da glicemia de ratos diabéticos induzidos por estreptozootocina pois, ao final do estudo, os níveis glicêmicos dos animais tratados com extratos aquoso e hidroalcoólico de suas folhas foram maiores que os do grupo controle branco diabético.

O diabetes mellitus é um distúrbio metabólico crônico, caracterizado por níveis elevados de glicemia pela deficiência e/ou resistência à insulina, que afeta aproximadamente 3\% da população mundial e a torna umas das doenças não contagiosas mais comuns. A hiperglicemia ocorre devido ao débito hepático alterado de glicose e à captação diminuída de glicose pelo músculo esquelético com síntese reduzida de glicogênio. Quando a reabsorção renal de glicose ultrapassa o seu limiar ocorre glicosúria, causando uma diurese osmótica que leva à poliúria e polidipsia. A morbidade associada ao diabetes de longa duração decorre de várias complicações graves, como disturbios macrovasculares, microangiopatia, retinopatia, nefropatia e neuropatia. A hipertensão coexistente leva à lesão renal progressiva, portanto o seu tratamento diminui a evolução da nefropatia diabética ( RANG et al., 2000). A maior parte das evidências 
experimentais e clínicas disponíveis sugere que as complicações representam uma consequiência dos distúrbios metabólicos, principalmente da hiperglicemia. Em virtude disso, estudos envolvendo substâncias com ação hipoglicemiante tornam-se imprescindíveis na tentativa de proporcionar maior conforto ao doente diabético.

Os rins constituem um dos principais alvos do diabetes. A insuficiência renal ocupa o segundo lugar depois do infarto do miocárdio como causa de morte nesta doença. São observadas três lesões: (1) lesões glomerulares; (2) lesões vasculares renais, principalmente arterioloesclerose; e (3) pielonefrite, incluindo papilite necrosante.

As lesões glomerulares mais importantes consistem em espessamento da membrana basal dos capilares, esclerose mesangial difusa e glomeruloesclerose nodular. O espessamento da membrana basal do capilar glomerular é observado em todo o seu comprimento e pode ser detectada na microscopia eletrônica alguns anos após o inicio do diabetes, às vezes sem qualquer alteração da função renal. A esclerose mesangial difusa, associada ao espessamento da membrana basal, consiste em aumento difuso da matriz mesangial com proliferação das células mesangiais. A glomerulosclerose nodular é caracterizada por depósitos arredondados de matriz na periferia dos glomérulos, PAS positivos e geralmente com células mesangiais aprisionadas, semelhantes a bolas, no interior do eixo mesangial do lóbulo, empurrando as alças capilares glomerulares para a periferia. Constitui uma importante causa de morbidade e mortalidade e, ao contrário da forma difusa, que também pode ser observada em associação à idade avançada e hipertensão, implica a presença de diabetes para todos os fins práticos. Ocorre glomerulosclerose difusa em glomérulos não afetados pela nodular. A glomerulosclerose avançada está associada à isquemia tubular e fibrose intersticial. Além disso, os pacientes com glicosúria não controlada podem reabsorver a glicose e armazená-la como glicogênio no epitélio tubular, sem alteração da função do túbulo. Quando a glomerulosclerose se torna pronunciada os pacientes apresentam síndrome nefrótica caracterizada por proteinúria, hipoalbuminemia e edema. A aterosclerose e a arterioloesclerose renal constituem parte do comprometimento sistêmico dos vasos sanguíneos em diabéticos e afeta as arteríolas aferente e eferente, nesta última raramente encontrada em indivíduos não diabéticos. A pielonefrite é uma inflamação aguda ou crônica dos rins, que habitualmente surge no tecido intersticial e, a seguir, dissemina-se afetando os túbulos. É mais comum e mais grave nos diabéticos do que na população geral. Um padrão particular de pielonefrite aguda, a papilite necrosante (ou necrose papilar), é muito mais prevalente em diabéticos (KUMAR et al., 2000).

Maeda et al. (2003) observaram em camundongos nonobese diabetic, lesões renais progressivas na fase aguda do diabetes mellitus, sem insulinoterapia. Evidenciaram um aumento 
gradual nas concentrações de creatinina, uréia e nitrogênio plasmáticos, hipertrofia renal e insignificante injúria glomerular nos estágios precoces da doença, assim como alterações estruturais na porção reta do túbulo proximal em estágios mais avançados da fase aguda. A mácula densa diminuiu no decorrer do tempo. Kumar et al. (2005) descreveram que no diabetes mellitus encontra-se glicogênio nas células epiteliais das porções distais dos túbulos contornados proximais e, às vezes, na porção descendente da alça de Henle, assim como nas células hepáticas, células $\beta$ das ilhotas de Langerhans e nas fibras musculares cardíacas. O glicogênio é uma fonte de energia presente no citoplasma de disponibilidade imediata e depósitos intracelulares de glicogênio em excesso são vistos em pacientes com anormalidade no metabolismo da glicose ou do glicogênio, como no diabetes mellitus.

No que diz respeito à indução do diabetes mellitus, Furlan (2001) relatou que grande parte das alterações que aparecem após o tratamento com estreptozootocina são decorrentes da sua lesão tóxica da sobre as células $\beta$, ao se acumular nas porções centrais das ilhotas pancreáticas. Seus efeitos do incluem hiperglicemia, aumento progressivo da glicosúria e do volume urinário, o peso corporal dos animais tende a diminuir e lipemia. Negri Marles ; Farnsworth (2005), após revisão, sugeriram que a estreptozootocina estimula a produção de radicais livres, o que leva a destruição e disjunção das células $\beta$. Este xenobiótico tem sido usado para induzir o diabetes com concomitante deficiência de insulina.

Bleasel ; Yong (1982) relataram que ratos que se tornaram diabéticos com uma única dose de estreptozootocina desenvolveram alterações morfológicas renais com sutis diferenças quando comparadas àquelas observadas em doenças renais de pacientes diabéticos humanos. A degeneração tubular precoce situava-se no túbulo contorcido distal em vez de no proximal. Além disso, lesões glomerulares mostraram depósitos lineares de IgG e albumina na membrana basal em vez de no mesângio. Rasch (1984), ao pesquisar o rim de ratos induzidos ao diabetes mellitus por estreptozootocina evidenciou, após 50 dias da indução, aumento no peso dos rins, no comprimento dos túbulos contorcidos proximais e no comprimento dos túbulos contorcidos distais, os quais se mostraram anormais no córtex e na faixa externa da medula. Células anormais foram também encontradas na mácula densa deste túbulo e se mostraram tanto vazias como repletas de material PAS-positivo, digerível pela $\alpha$-amilase. Pela microscopia eletrônica o citoplasma das células continha grânulos de glicogênio e apresentava grande redução nas pregas basais e em algumas organelas. Estas lesões tubulares poderiam contribuir para o desenvolvimento das mudanças funcionais do rim no diabetes. Obineche et al. (2001) verificaram após quatro semanas da indução de ratos ao diabetes mellitus pelo uso da estreptozootocina, túbulos dilatados no córtex dos rins dos animais diabéticos com uma 
destruição significativa dos túbulos contorcidos distais. Após oito meses, observou-se espessamento da membrana basal, perda dos processos podocíticos, ruptura das pregas basais dos túbulos e as mitocôndrias a elas relacionadas além de fibrose destes. Em relação aos efeitos nas organelas celulares, Corrêa (1988) evidenciou que a glândula submandibular de ratos Wistar diabéticos estreptozootocínicos respondeu precariamente a secretagogos (substância P, acetilcolina e noradrenalina), devido às lesões necróticas no retículo endoplasmático rugoso. Grinblat ; Stoppani (1989) verificaram que a velocidade do fluxo de cálcio foi significativamente maior nas mitocôndrias hepáticas de ratos normoglicêmicos quando comparada a de animais hiperglicêmicos estreptozootocínicos. Shen et al. (2004) narraram que o estresse no retículo endoplasmático rugoso está relacionado com várias patologias, entre as quais se encontra o diabetes mellitus.

Visto que o controle rigoroso da glicemia constitui até agora a única esperança de evitar as complicações fatais do diabetes mellitus (KUMAR et al., 2000) alguns estudos têm sido realizados com substâncias de ação hipoglicemiante, provavelmente no sentido de recuperar a produção de insulina. Neste sentido, Bolkent et al. (2000) mostraram que a Beta vulgaris L. var. cicla (chard) pode diminuir a glicemia pelo aumento da secreção de insulina e regeneração das células $\beta$ do pâncreas. Kaneto et al. (1999) evidenciaram o efeito dos antioxidantes N-acetil-Lcisteína (NAC) e vitaminas E e C sobre a preservação da função das células beta pelo aumento de sua massa beta nos ratos diabéticos tratados. Isso sugere supressão da apoptose dessas células.

Parshad et al. (1999) encontraram melhora significativa nos pesos e diminuição da mortalidade de ratos com diabetes induzida por estreptozootocina tratados com extrato aquoso do Neem, porém, não ocorreu normalização dos níveis glicêmicos. Khosla et al. (2000) observaram efeito hipoglicemiante do extrato das folhas e do óleo das sementes de Azadirachta indica em coelhos diabéticos induzidos pela aloxana, tanto no grupo tratado preventivamente 2 semanas antes da indução quanto no tratado por 4 semanas após a indução, podendo ser benéfica no controle e na prevenção do aparecimento da doença. Hussain (2002) demonstrou que o tratamento aquoso do Neem tem efeito favorável sobre a glicemia e tolerância à glicose, como também reduziu os lipídios séricos, o peso corporal e reverteu completamente as anormalidades da retina e a inflamação das patas dos animais. Negri apud Chattopadhay (2005) entendeu que o efeito hipoglicemiante do extrato das folhas de Azadirachta indica deve-se ao bloqueio do efeito inibitório da serotonina sobre a liberação de insulina mediada pela glicose.

Em relação ao tratamento homeopático do diabetes mellitus, Santos (1990) verificou ação hipoglicemiante da aloxana em ultra alta diluições em sistemas dinamizados (aloxana 6CH) em ratos diabéticos. 
Quanto ao epitélio dos túbulos contorcidos proximais, Lopes (2004) descreveu como sendo formado por células arredondadas, poliédricas, um pouco alongadas ou ovóides, medindo de 15 a 30 micrômetros. O núcleo é grande, redondo, às vezes excêntrico e o citoplasma granuloso. Martins ; Azoubel (2006), ao realizarem a cariometria no néfron de fetos de ratas tratadas com aspartame, encontraram para alguns parâmetros analisados nas células dos túbulos contorcidos proximais, em animais do grupo controle, os seguintes valores, a saber: diâmetro maior $(9,11 \mu \mathrm{m})$; diâmetro menor $(7,66 \mu \mathrm{m})$; diâmetro médio $(8,36 \mu \mathrm{m})$; relação $\mathrm{D} / \mathrm{d}(1,22)$; volume $\left(341,00 \mu \mathrm{m}^{3}\right)$; área $\left(56,90 \mu \mathrm{m}^{2}\right)$; perímetro $(26,50 \mu \mathrm{m})$; relação v/a $(5,58)$; excentricidade $(0,52)$; coeficiente de forma $(0,98)$ e índice de contorno $(3,58)$. Evidenciaram também para a cariometria das células dos túbulos contorcidos distais, para os mesmos parâmetros, os seguintes resultados, como seguem: diâmetro maior $(7,15 \mu \mathrm{m})$; diâmetro menor $(5,34 \mu \mathrm{m})$; diâmetro médio $(6,15 \mu \mathrm{m})$; relação $\mathrm{D} / \mathrm{d}(1,40)$; volume $\left(128,00 \mu \mathrm{m}^{3}\right)$; área $\left(30,20 \mu \mathrm{m}^{2}\right)$; perímetro $(19,8$ $\mu \mathrm{m})$; relação v/a $(4,10)$; excentricidade $(0,64)$; coeficiente de forma $(0,95)$ e índice de contorno $(3,63)$.

\section{MATERIAL E MÉTODOS}

Preparou-se dois extratos de Azadirachta indica, A. Juss, um aquoso e outro etanólico, com as folhas do Nim cultivadas e fornecidas pela EMBRAPA-CNPAF, que previamente passaram por um processo de estabilização à sombra em um ambiente coberto e ventilado. Após esta secagem e posterior trituração das folhas, foi preparado um extrato etanólico a 70\% (p/p) por percolação, até o esgotamento do ativo, numa velocidade de 8 gotas por minuto e em seguida este foi concentrado até a obtenção de um extrato mole. O outro foi um extrato aquoso, utilizando a água destilada para realizar a percolação até o esgotamento do ativo, nas mesmas condições anteriores, e posteriormente este extrato aquoso foi liofilizado.

Os animais de experimentação foram 25 ratos albinos, machos, da raça Wistar pesando entre 200 e 250 gramas provenientes do Biotério Central do Campus de Botucatu - UNESP. Estes foram divididos em grupos de 5 animais, adaptados em gaiolas no Biotério do Departamento de Morfologia e Fisiologia Animal da Faculdade de Ciências Agrárias e Veterinárias, Campus de Jaboticabal - UNESP, com temperatura controlada e ciclo de claroescuro de 12 horas, com fornecimento de ração e água ad libitum, durante 5 dias.

Após o período de adaptação, os animais foram deixados em jejum alimentar de 14 a 16 horas, e coletou-se, através da artéria infraorbitária, amostras de sangue (1mL) para a determinação da glicemia pelo método de KING; GARNER ( 1947 ), após leve anestesia 
inalatória por éter. Em seguida, foi administrada a 20 ratos, $35 \mathrm{mg} / \mathrm{kg}$ de estreptozootocina diluída em tampão citrato de sódio ( $\mathrm{pH} 4,5)$, intravenosamente, no seio venoso do pênis, com os animais ainda anestesiados. Os outros cinco ratos serviram como grupo controle branco. Após cinco dias, coletou-se sangue, como anteriormente, para a determinação da glicemia. Os animais que apresentaram hiperglicemia foram separados em grupos que receberam tratamento oral uma vez por dia, com os diferentes extratos de Azadirachta indica, A. Juss e com estreptozootocina em ultra alta diluições em sistemas dinamizados (estreptozootocina $6 \mathrm{CH}$ ).

Todos os animais foram tratados diariamente, por via oral $(0,2 \mathrm{~mL} / 100 \mathrm{~g}$ de animal), através de gavagem, a saber: os grupo controle branco e controle branco diabético receberam água; um grupo recebeu extrato aquoso de Azadirachta indica, A. Juss a 10\%; outro grupo foi tratado com extrato hidroalcoólico (70\%) de Azadirachta indica, A. Juss a $10 \%$ e o último grupo com estreptozootocina em ultra alta diluições em sistemas dinamizados (estreptozootocina 6 $\mathrm{CH})$. Este procedimento foi realizado durante 30 dias.

No $31^{\circ}$ dia, os animais foram sacrificados e o rim, após coletado, foi fixado em solução de Bouin por 24 horas e processado, rotineiramente, para a inclusão em parafina. Após a microtomia semi-seriada, a intervalos de $110 \mu \mathrm{m}$, os cortes histológicos, à espessura de $7 \mu \mathrm{m}$, foram corados pela técnica da hematoxilina-eosina (HE) e do ácido periódico de Schiff (PAS) (TOLOSA et al., 2003) e fotomicrografados com auxílio de um fotomicroscópio da LEICA DM 5000 B. Para cada animal foram confeccionadas cinco lâminas com cinco cortes histológicos, ou seja, 25 cortes por animal. A análise cariométrica será realizada nos túbulos contorcidos proximais, medindo-se a área $\left(\mu \mathrm{m}^{2}\right)$, perímetro $(\mu \mathrm{m})$, diâmetro máximo $(\mu \mathrm{m})$, diâmetro mínimo $(\mu \mathrm{m})$ e fator de forma. A morfometria também será realizada na espessura $(\mu \mathrm{m})$ deste segmento do néfron.

O fator de forma, cuja fórmula é expressa matematicamente por $\frac{(\text { perímetro })^{2}}{(4 . \pi \text {.área })}$, está programado, como os demais parâmetros, na memória do programa Image Pro-plus. O menor valor deste fator é igual a um, significando que a forma do citoplasma e/ou do núcleo se assemelha à forma de um círculo. Este fator é calculado, indiretamente, a partir da área do círculo, que tem por equação п. $\mathrm{R}^{2}$, como também a partir do perímetro do círculo, com a equação 2.п.R. Pela substituição da área e do perímetro obtêm-se:

Fator de forma: $\frac{(2 \cdot \pi \cdot R)^{2}}{4 \cdot \pi \cdot\left(\pi \cdot R^{2}\right)}=\frac{\left(4 \cdot \pi^{2} \cdot R^{2}\right)}{\left(4 \cdot \pi \cdot \pi \cdot R^{2}\right)}=\frac{\left(4 \cdot \pi^{2} \cdot R^{2}\right)}{\left(4 \cdot \pi^{2} \cdot R^{2}\right)}=1$

Quando este fator for maior que a unidade, entende-se que a forma do citoplasma e/ou do núcleo não é circular. 
O experimento foi realizado conforme o delineamento inteiramente casualizado, com 5 tratamentos e 5 repetições. As médias foram comparadas mediante o teste de Tukey a 5\% de probabilidade de acordo com Pimentel Gomes (2000).

\section{RESULTADOS E DISCUSSÃO}

Os resultados obtidos pela morfometria do núcleo das células dos túbulos contorcidos proximais, bem como de sua espessura estão apresentados nas tabelas 1 e 2 , respectivamente.

A análise de variância dos resultados indicados na tabela 1, referentes aos parâmetros mensurados nos núcleos das células dos túbulos contorcidos proximais, revelou que para o teste F houve diferenças significativas entre os tratamentos. Estas diferenças foram ao nível de $1 \%$ de probabilidade $(\mathrm{p}<0,01)$ somente para a área e ao nível de $5 \%$ de probabilidade $(\mathrm{p}<0,05)$ somente para o diâmetro mínimo. Entretanto, o diâmetro máximo, o perímetro e o fator de forma não diferiram significativamente $(p>0,05)$ entre os tratamentos.

O teste de Tukey mostrou diferenças significativas entre os grupos experimentais $(\mathrm{p}<0,05)$ para a maioria dos parâmetros. Observou-se para a área diferença significativa $(\mathrm{p}<0,05)$ entre o grupo controle branco e o controle branco diabético, o qual também diferiu dos grupos tratados com extrato hidroalcoólico (70\%) de Azadirachta indica, A. Juss a $10 \%$ e do grupo tratado com estreptozootocina $6 \mathrm{CH}$. O diâmetro mínimo apresentou diferença significativa $(\mathrm{p}<0,05)$ na comparação entre o grupo controle branco e o grupo controle branco diabético e também entre este último grupo e o tratado com estreptozootocina $6 \mathrm{CH}$.

Em relação ao diâmetro máximo, perímetro e fator de forma não foram evidenciadas diferenças significativas $(\mathrm{p}>0,05)$ entre os grupos experimentais.

A análise dos resultados obtidos na tabela 2, referentes aos valores médios obtidos para a espessura dos túbulos contorcidos proximais, revelou pelo teste $\mathrm{F}$ ao nível de $5 \%$ de probabilidade $(\mathrm{p}<0,05)$ que houve diferenças significativas entre os grupos experimentais, ou seja. Na comparação entre os grupos tratados com extrato aquoso e com extrato hidroalcoólico notou-se diferença significativa, pelo teste de Tukey a 5\% de probabilidade $(\mathrm{p}<0,05)$, porém, essa diferença não foi encontrada comparando-se os mesmos grupos tratados com os demais $(\mathrm{p}>0,05)$.

A cariometria revelou que os valores médios encontrados para o fator de forma foram maiores para o grupo controle branco, entretanto, foram semelhantes estatisticamente entre todos os grupos experimentais. Estas evidências estão de acordo com os relatos de Lopes ( 2004 ) e 
Junqueira; Carneiro (2008) em relação à forma arredondada do núcleo destas células. Ainda, com referência à cariometria, os valores médios encontrados para os parâmetros analisados, em todos os grupos neste estudo, foram inferiores aos encontrados por Martins ; Azoubel (2006). A morfometria comprovou que o grupo controle branco apresentou os maiores valores médios para todos os parâmetros analisados, comparado aos demais grupos experimentais.

TABELA 1- Valores de F, coeficiente de variação (CV), médias e diferença mínima significativa (DMS) a 5\% obtidos na análise de variância para os parâmetros medidos nos núcleos das células dos túbulos contorcidos proximais dos rins de ratos machos albinos Wistar, dos grupos controles e tratados.

\begin{tabular}{lccccc}
\hline \hline \multicolumn{1}{c}{ Tratamento } & $\begin{array}{c}\text { Área } \\
\left(\boldsymbol{\mu \mathbf { m } ^ { 2 } )}\right.\end{array}$ & $\begin{array}{c}\text { Diâmetro } \\
\text { Máximo }(\boldsymbol{\mu m})\end{array}$ & $\begin{array}{c}\text { Diâmetro } \\
\text { Mínimo }(\boldsymbol{\mu m})\end{array}$ & $\begin{array}{c}\text { Perímetro } \\
(\boldsymbol{\mu m})\end{array}$ & $\begin{array}{c}\text { Fator de } \\
\text { forma }\end{array}$ \\
\hline \hline Controle Branco & $30,1392 \mathbf{b}$ & $6,7100 \mathbf{a}$ & $5,6120 \mathbf{b}$ & $23,11025 \mathbf{a}$ & $1,4112 \mathbf{a}$ \\
$\begin{array}{l}\text { Controle Branco } \\
\text { Diabético }\end{array}$ & $33,0825 \mathbf{a}$ & $7,0500 \mathbf{a}$ & $6,0200 \mathbf{a}$ & $24,1475 \mathbf{a}$ & $1,40295 \mathbf{a}$ \\
& & & & & \\
$\begin{array}{l}\text { Extrato Aquoso de } \\
\text { Azadirachta indica }\end{array}$ & $31,12 \mathbf{a b}$ & $6,82250 \mathbf{a}$ & $5,8275 \mathbf{a b}$ & $22,9375 \mathbf{a}$ & $1,34685 \mathbf{a}$
\end{tabular}

\section{Extrato}

Hidroalcoólico de $\quad 29,1975 \mathbf{b} \quad 6,80750 \mathbf{a} \quad 5,8675 \mathbf{a b} \quad 22,6875 \mathbf{a} \quad 1,40545 \mathbf{a}$ Azadirachta indica

\begin{tabular}{lrrrrr}
$\begin{array}{l}\text { Estreptozootocina } \\
\text { 6 CH }\end{array}$ & $30,6425 \mathbf{b}$ & $6,74750 \mathbf{a}$ & $5,6150 \mathbf{b}$ & $22,7225 \mathbf{a}$ & $1,341625 \mathbf{a}$ \\
\hline \hline Teste F & $9,53 * *$ & $2,87 N S$ & $3,89 *$ & $2,92 \mathrm{NS}$ & $0,73 \mathrm{NS}$ \\
\hline $\mathbf{C V}$ & 3,0334834 & 2,2885829 & 3,0683727 & 3,0301012 & 5,7948843 \\
\hline DMS (5\%) & 2,0425 & 0,3412 & 0,3878 & 1,5297 & 0,1748 \\
\hline \hline
\end{tabular}

NS: não significativo

*: significativo a $5 \%$ de probabilidade

**: significativo a $1 \%$ de probabilidade

Médias seguidas pelas mesmas letras nas colunas não diferem significativamente entre si pelo Teste de Tukey a 5\% de probabilidade. 
TABELA 2- Valores de F, coeficiente de variação (CV), médias e diferença mínima significativa (DMS a 5\%) obtidos nas análises de variância para a espessura dos túbulos contorcidos proximais de ratos machos albinos Wistar, dos grupos controles e tratados.

Tratamento

Espessura $(\mu \mathrm{m})$

Controle Branco

$13,5510 \mathbf{a b}$

Controle Branco Diabético

$13,2850 \mathbf{a b}$

Extrato Aquoso de Azadirachta indica

$13,7400 \mathbf{a}$

Extrato Hidroalcoólico de Azadirachta indica

$11,6775 \mathbf{b}$

Estreptozootocina 6 CH

$12,7975 \mathbf{a b}$

Teste F

$3,44^{*}$

CV

6,8355428

DMS (5\%)

1,9418

*: significativo a $5 \%$ de probabilidade

Médias seguidas pelas mesmas letras nas colunas não diferem significativamente entre si pelo Teste de Tukey a 5\% de probabilidade.

\section{CONCLUSÃO}

Conclui-se, mediante os resultados morfométricos obtidos, que alguns parâmetros analisados diferiram entre os grupos no núcleo das células dos túbulos contorcidos proximais bem como na espessura das células destes túbulos. Os valores obtidos foram menores dos que os descritos em outro estudo. O grupo controle branco apresentou, na cariometria, os maiores valores médios para todos os parâmetros, porém não se pode afirmar que o diabetes mellitus diminua drasticamente as medidas dos núcleos dessas células.

\section{AGRADECIMENTOS}

Ao apoio financeiro concedido pela FAPESP - Fundação de Amparo à Pesquisa do Estado de São Paulo, por meio de bolsa de Iniciação Científica. 


\section{REFERÊNCIAS}

BACHA JUNIOR, W. J.; BACHA, L. M. Atlas colorido de histologia veterinária. 2. ed. São Paulo: Roca, 2003. 457 p.

BLEASEL, A. F.; YONG, L.C. J. Streptozotocin induced diabetic nephropathy and renal tumors in the rat. Jounal of Cellular and Molecular Life Sciences, v. 38, n. 1, p. 129-130, 1982.

BOLKENT, S.et al. Effects of chard (Beta vulgaris L. var. cicla) extract on pancreatic $\beta$ cells in streptozotocin-diabetic rats: a morphological and biochemical study. Journal of Ethnopharmacology, v. 73, n. 1-2, p. 251-259, 2000.

CHATTOPAHYAY, R. R. Comparative evaluation of some blood sugar lowering agents of plant origin. Journal of Ethnopharmacology. v. 67, n. 3, p. 367-372, 1999.

CHOPRA, R. N. The Nim (Melia azadirachta L. Meliaceae) In: Chopra, R. N. Indigenous drugs of India. 2. ed. Nova Delhi: Academia Publishers, 1958, p. 360-363.

CORRÊA, M. S. N. P. Alterações induzidas pelo diabetes insulino-dependentes na glândula submandibular do rato. 1988. 239 f. Tese (Doutorado em Odontopediatria) - Faculdade de Odontologia, Universidade de São Paulo.

COTRAN, R. S.; KUMAR, V.; ROBBINS, S. L. Robbins: patologia estrutural e funcional. 6. ed. Rio de Janeiro: Guanabara Koogan, 2000. 1400 p.

CUNNINGHAM, J. G. Tratado de fisiologia veterinária. Rio de Janeiro: Guanabara Koogan, 1999. $528 \mathrm{p}$.

DI STASI, L. C. Plantas medicinais: arte e ciência: um guia de estudo interdisciplinar. São Paulo: Edunesp, 1996. 230 p.

DYCE, K. M.; SACK, W. O.; WENSING, C. J. G. Tratado de anatomia veterinária. 3. ed. Rio de Janeiro: Elsevier, 2004. 813 p.

FARMACOPÉIA homeopática brasileira. 2. ed. São Paulo: Atheneu, 1997.

FURLAN, M. M. D. P. A estreptozootocina como agente diabetogênico. Arquivo de Ciências da Saúde Unipar, v. 5, n. 2, p. 197-201, 2001.

GRINBLAT, L.; STOPPANI, A. O. M. Diabetes and calcium transportation in liver mitochondria. Medicina, v. 49, n. 1, p. 21-27, 1989.

HUSSAIN, H. E. M. A. Reversal of diabetic retinopathy in streptozotocin induced diabetic rats using traditional Indian anti-diabetic plant, Azadirachta indica, A. Juss (L.). Indian Journal of Clinical Biochemistry, v. 17, n. 2, p. 115-123, 2002.

JUNQUEIRA, L. C.; CARNEIRO, J. Histologia básica: texto e atlas. 11. ed. Rio de Janeiro: Guanabara Koogan, 2008, 524 p. 
KANETO, H.et al. Beneficial effects of antioxidants in diabetes. Possible protection of pancreatic beta-cells against glucose toxicity. Diabetes. v. 48, n. 12, p. 2398-2406, 1999.

KHOSLA, P.et al. A study of hypoglycaemic effects of Azadirachta indica, A. Juss (Neem) in normaland alloxan diabetic rabbits. Indian Journal of Physiology and Pharmacology, v. 44, n. 1 , p. 69-74, 2000.

$\mathrm{KOCH}, \mathrm{C} . \mathrm{K}$. El arbor de la India (Azadirachta indica) y su utilización potential en el Equador con especial referencia a las propriedades plaguicidas de jus extratos. Equador: convênio GTZ/MAG. 15 p., 1990.

KUMAR, V.; ABBAS, A. K.; FAUSTO, N. Robins e Cotran: patologia: bases patológicas das doenças. 7. ed. Rio de Janeiro: Elsevier, 2005. 1592 p.

LOPES, H. J. J. O laboratório clínico na avaliação da função renal. Belo Horizonte: Gold Analisa Diagnóstica, 2004, 27 p.

MAEDA, M.et al. Renal Lesions in Spontaneous Insulin-dependent Diabetes mellitus in the Nonobese Diabetic Mouse: Acute Phase of Diabetes. Veterinary Pathology, v. 40, p.187-195, 2003.

MARTINS, E. R.et al. Plantas medicinais, Viçosa: UFV, 1998. 220 p.

MARTINS, M. R. I.; AZOUBEL, R. Efeitos do Aspartame no rim fetal de ratos: Estudo Cariométrico. Jornal Brasileiro de Nefrologia. São Paulo, v. 28, n. 3, p. 151-157, 2006.

NEGRI, G. Diabetes mellitus: plantas e princípios ativos naturais hipoglicemiantes. Revista Brasileira de Ciências Farmacêuticas, v. 41, n. 2, p. 121-142, 2005.

OBINECHE, E. N.et al. Morphological changes in the rat kidney following long-term diabetes. Archives of Physiology and Biochemistry, v.109, p. 241-245, 2001.

PARSHAD, O.; WEST, E.; GARDNER, M. Effects o aqueous extract of Neem (Azadirachta indica, A. Juss ) on streptozotocin induced diabetic rats. In: ANNUAL RESEARCH CONFERENCE, 8, 1999, Kingston. Eighth Annual Research Conference 1999. Mona: University of the West Indies, Faculty of Medical Sciences, 1999.

PIMENTEL GOMES, F. Curso de estatística experimental. 14. ed. Piracicaba: Pimentel Gomes, 2000. 477 p.

RAGASA, C. Y.et al. Tetranortriterpenoids from Azadirachta indica, A. Juss .Phytochemistry, v. 46, n. 3, p. 555-558, 1997.

RASH, R. Tubular lesions in streptozotocin-diabetic rats. Diabetologia, v. 27, n. 1, p. 32-37, 1984.

SANTOS, E. Action hypoglycémiante de l'alloxane $6 \mathrm{CH}$ sur les rats diabétiques alloxaniques. Homeopathie, v. 3, p. 38-39, 1990. 
SAXENA, R. C. Scope of Nim developing countries. Paper presented at world nim conference Souvenir-Bengalore, 1993. p. 24-28.

SCHMUTTERER, H. Properties and potential of natural pestcides from the nim tree (Azadirachta indica). Annual Review of Entomology, v. 35, p. 271-297, 1990.

SHEN, X.; ZHANG, K.; KAUFMAN, R. J. The unfolded protein response: a stress signaling pathway of the endoplasmic reticulum. Journal of Chemical Neuroanatomy, v. 28, p. 79-92, 2004.

TOLOSA, E. M. C.et al. Manual de técnicas para histologia normal e patológica. 2. ed. São Paulo: Manole, 2003. 331 p. 
